\title{
INTERPRETASI KALOSARA DALAM RUMAH ADAT TOLAKI
}

\author{
Sachrul Ramadan \\ Jurusan Arsitektur Fakultas Teknik Universitas Halu Oleo Kendari \\ email: sachrul.ramadan@uho.ac.id
}

\begin{abstract}
ABSTRAK. Etnis Tolaki, adalah salah satu dari tiga kelompok etnis utama di Sulawesi Tenggara yang memiliki gaya dan bentuk budaya yang spesifik. Bentuk budaya yang spesifik diwujudkan dalam obyek yang menjadi simbol budaya disebut Kalo Sara. Kalo Sara terdiri dari tiga elemen benda atau bahan, yaitu Rotan, Kain Putih dan Lingkaran (terbuat dari Rotan) ketiga komponen bahan dan benda tersebut merupakan bahasa simbolis yang melambangkan semua aspek kehidupan sosial masyarakat Tolaki. Penelitian ini akan mengeksplorasi nilai ruang dan bentuk rumah adat Tolaki dalam kaitannya dengan Kalo Sara sebagai unsur tertinggi dalam Tatanan Budaya Tolaki. Subyek yang akan diteliti adalah penafsiran Kalo Sara sebagai unsur budaya tertinggi dalam esensi budaya terhadap komposisi ruang, bentuk dan makna dalam rumah tradisional Tolaki. Hasil penelitian menemukan bahwa Kalo Sara sebagai simbol budaya di komunitas Tolaki sangat erat dan melekat dalam konfigurasi ruang rumah tradisional Tolaki. Inti dari ruang yang mendefinisikan sifat Kalo Sara dari seluruh pengaturan ruang disebut istilah Siwolembatohu.
\end{abstract}

Kata Kunci: Rumah Tolaki, Siwolembatohu, Kalo Sara

ABSTRACT. Ethnic Tolaki, is one of the three main ethnic groups in southeast Sulawesi that have a specific cultural style and form. A particular cultural form is manifested in an object that becomes a cultural symbol called Kalo Sara. If Sara is made up of three elements of matter or material, namely Rattan, White cloth and Circle (made of Rattan) the three components of the material and the object is a symbolic language symbolizing all aspects of the social life of the Tolaki community. This research will explore the value of space and customs house form Tolaki concerning Kalo Sara as the highest element in the Tolaki Cultural Organization. The subjects to be studied are the interpretation of Kalo Sara as the most top cultural element in the essence of culture to the composition of space, form, and meaning in Tolaki traditional house. The results of the study found that Kalo Sara as a cultural symbol in the Tolaki community is intimately tied to the traditional Tolaki house space configuration. The core of the space that defines the Kalo Sara nature of the whole spatial arrangement is called the Siwolembatohu term.

Keywords: Rumah Tolaki, Siwolembatohu, Kalo Sara.

\section{PENDAHULUAN.}

Etnis Tolaki, adalah salah satu dari tiga etnis besar di wilayah Sulawesi Tenggara yang mempunyai bentuk dan corak kehidupan budaya yang spesifik. Makna kehidupan yang spesifik tertuang dalam benda yang menjadi simbol budaya disebut Kalo Sara. Kalo Sara tersusun atas tiga unsur benda atau bahan yaitu Anyaman Rotan, Kain Putih dan Lingkaran (terbuat dari Rotan) yang syarat akan makna baik dalam susunan dan bahannya. Kalo adalah bahasa simbolik yang menyimbolkan segala aspek dari hakikat kehidupan sosial masyarakat tolaki. Penelitian ini akan menggali nilai ruang dan bentuk rumah tradisional Tolaki yang bersifat culturalspesific, dalam kaitannya dengan Kalo Sara sebagai simbol tertinggi dalam kebudayaan Tolaki. Di dalam kalo tersirat beberapa makna yang terkait dengan hidup dan kehidupan orang Tolaki sebagai contoh : lambang persatuan dan kesatuan tercermin didalam makna simbolik dari lingkaran rotan, keikhlasan dan kesucian tercermin didalam makna simbolik kain putih dan ide-ide kemakmuran dan kesejahteraan tercermin didalam makna simbolik dari wadah anyaman dimana lingkaran rotan dan kain putih diletakkan. [1]

Pokok masalah yang akan dikaji adalah interpretasi Kalo Sara sebagai unsur budaya tertinggi dalam hakekat kebudayaan terhadap susunan ruang, bentuk dan maknanya dalam Rumah tradisional tolaki.

Tujuan dari penelitian ini adalah menganalisa secara holistic unsur pembentuk rumah dan bagaimana kedudukan Kalo Sara sebagai simbol tertinggi dalam kebudayaan Tolaki terinterpretasi dalam bentuk

dan susunan ruang Rumah Tradisioanal Tolaki. Manfaat yang diharapkan pada penelitian ini adalah untuk memberikan 
pemahaman tentang konsep dasar arsitektur Tolaki, sehingga dapat menjadi petunjuk dalam pengembangan arsitektur lokal yang berkaitan dengan konsep kekinian dan diharapkan identitas lokal ini tetap lestari dan berkesinambungan.

\section{PENGARUH BUDAYA DAN RELIGI TERHADAP BENTUK RUMAH}

Rapoport mengemukakan bahwa rumah dan permukiman berhubungan erat dengan kebudayaan, antara lain terlihat pada pandangan hidup, konsepsi tentang dunia/alam semesta dan organisasi sosial dari masyarakat yang bersangkutan. Rapoport juga mengemukakan bahwa tata lingkungan merupakan penampilan fisik dari suatu system dan penataan bangunan merupakan suatu sifat dasar dari alam pikiran manusia. Penataan sering didasarkan atas hal yang suci, karena religi dan ritual menjadi pusat walaupun bagian-bagian lain juga memainkan peran, karena masyarakat tradisionil adalah religius maka lingkungan buatan yang dibuat mencirikan hal yang suci karena hal itulah yang menunjukkan makna yang paling berarti. [2]

Melalatoa dalam triyanto, mengemukakan konsepsinya bahwa suatu karya arsitektur, bukanlah sekedar hasil karya seni bangunan yang mengekspresikan tentang keindahan atau hal-hal yang bersifat fisik semata, melainkan didalamnya tersirat pesan-pesan budaya yang mengandung unsur system budaya masyarakat yang bersangkutan. [3]

\section{KALO SARA SEBAGAI EKSPRESI SIMBOLIK MASYARAKAT TOLAKI}

Kalo merupakan benda yang disakralkan oleh masyarkat Tolaki, ia terdiri atas tiga bagian yaitu; lilitan rotan yang membentuk lingkaran, kain putih dan anyaman berbentuk segi empat. Kalo adalah bahasa simbolik yang menyimbolkan segala aspek hakikat dari kehidupan sosial masyarakat tolaki oleh karena itu Kalo disimbolkan sebagai fokus kebudayaan Tolaki. Dijelaskan oleh Tarimana Rauf [1] :

a. bahwa Kalo Sara adalah symbol dari unsur-unsur keluarga inti (ayah, ibu dan anak), adat dalam kehidupan rumah tangga dan rumah tangga itu sendiri sebagai wadah kehidupan keluarga inti.

b. Kalo adalah symbol dari unsur kerabat, kalo adalah simbol dari kelompok kerabat ambilinial luas yang mengekspresikan kesatuan dan persatuan warga orang Tolaki asal satu nenek moyang

c. Kalo adalah symbol dari unsur pimpinan kelompok sosial kecil, adat dalam kehidupan kelompok kecil itu, dan wadah lingkungan kecil tempat tinggal warganya. Tiga unsur dari pimpinan itu adalah

- Tonomotuo (ketua Kelompok )

- Tamalaki (Kepala pertahanan )

- Mbu' akoi ( Dukun kelompok)

d. Pada tingkat kerajaan, kalo adalah symbol dari tiga unsur pimpinan kerajaan yaitu :

- Mokole (raja)

- Sulemandra (PM)

- Tutuwi Motaha (aparat pertahanan)

e. Kalo adalah juga simbol dari cita-cita politik kerajaan, yaitu Persatuan dan Kesatuan, Kesucian dan keadilan, Kemakmuran dan kesejahteraan

f. Kalo adalah ekspresi alam semesta dengan isinya, dimana alam semesta menurut orang Tolaki terdiri atas tiga bagian yaitu :

- Hanu mendoda (alam nyata)

- Hanu Metoku ( alam bayangan)

- Hanu Tehi (alam gaib)

Alam nyata menurut orang Tolaki terdiri atas tiga bagian yaitu :

- Lahuena (langit)

- Wawowuta (permukaan bumi)

- Puriwuta (dasar bumi)

Dijelaskan juga oleh Tarimana Rauf, Masyarakat tolaki mempunyai tujuh unsur kebudayaan yang menjadi tonggak dalam berkehidupan. Hakekat dari ketujuh unur kebudayaan tersebut sangat terkait dengan simbol Budaya Kalo Sara. Berikut gambar susunan Kalo Sara dan hubungannya dengan Konsep kebudayaan Masyarakat Tolaki.[1]

Pemahaman umum akan Fungsi sosial Benda Budaya yang bernama kalo sara, biasanya menjadi bagian kelengkapan yang harus disertakan dalam pelamaran, membuat kesepakatan dalam penyelesaian pertikaian dan Upacara adat khusus lainnya. Tanpa keikutsertaan benda budaya ini dalam kegiatan soial peradatan maka kegiatan tersebut tidak syah dan afdol. 


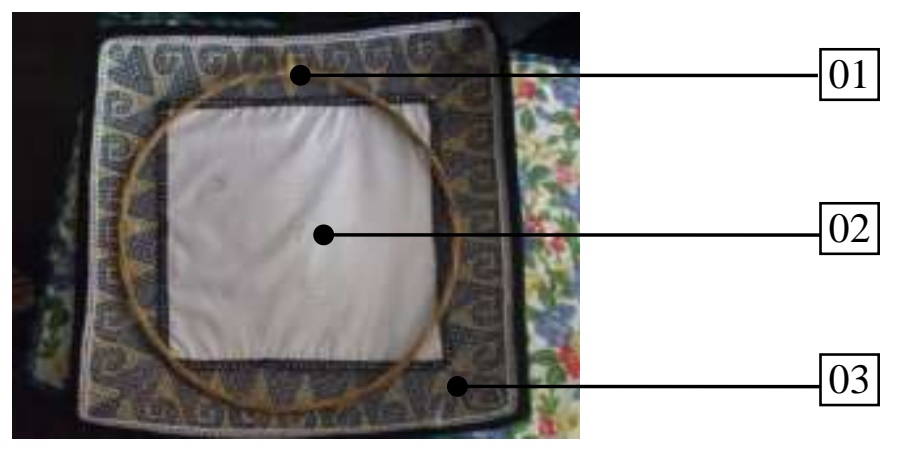

Lingkaran Rotan

Kain Putih

Anyaman

Gambar . 1. Kalo sebagai bahasa lambang dalam kebudayaan tolaki Sumber : Tarimana, R, 1993

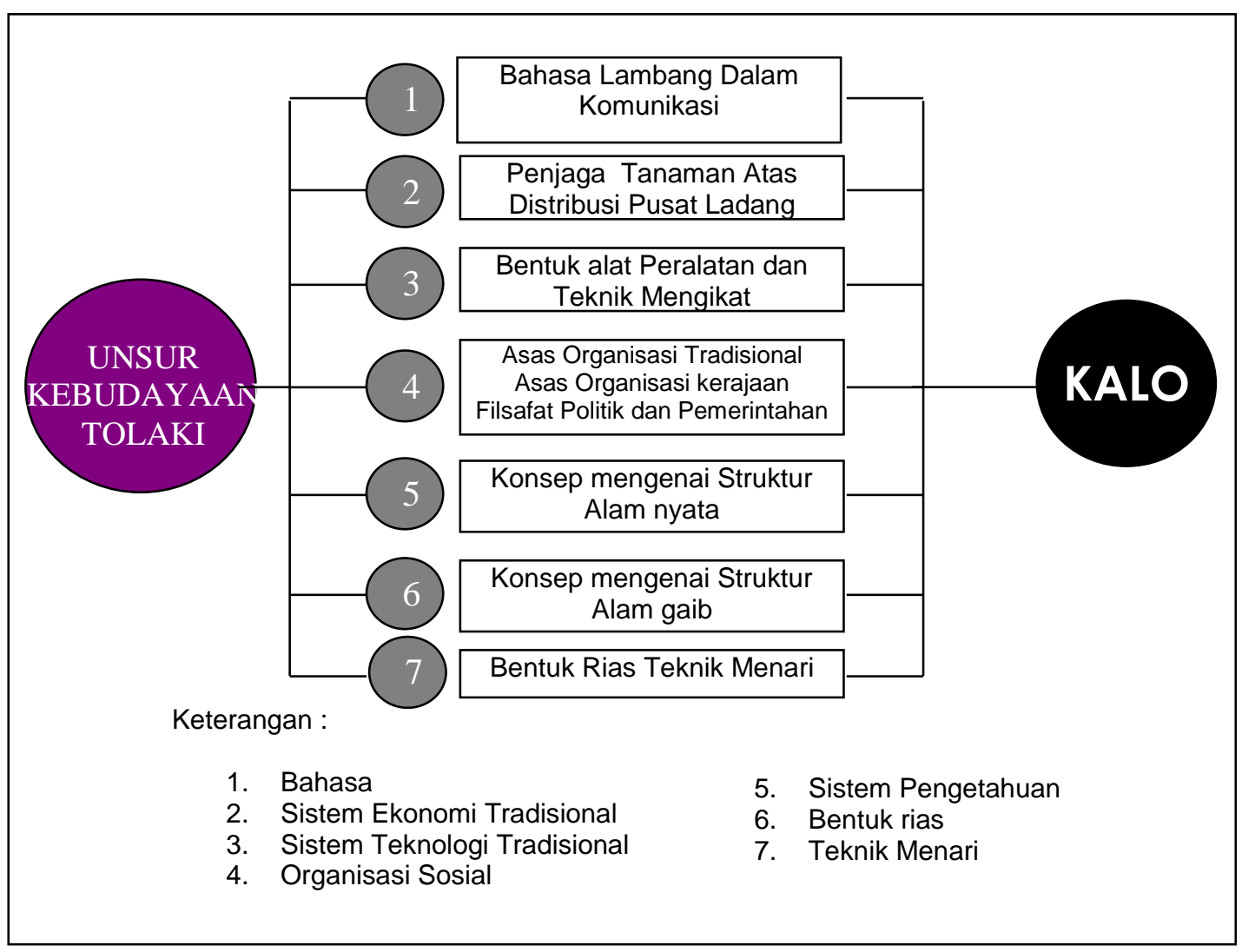

Gambar . 2. Hubungan 7 unsur Kebudayaan Tolaki terhadap Kalo Sumber : Tarimana, R, 1993

JENIS RUMAH TRADISIONAL ORANG TOLAKI

Mengutip pernyataan Tarimana Rauf dalam kebudayaan Tolaki dijelaskan bahwa :

- Nama Istana raja Konawe disebut Komali (rumah tempat bersemayam raja

- Nama Istana raja Mekongga disebut Laika'aha (rumah besar tempat berkumpul orang banyak. [1]
Mengutip pernyataan Lakebo dalam Arsitektur Tradisional Sulawesi Tenggara menjelaskan bahwa; Rumah tinggal dikalangan suku Tolaki di sebut "Laika" yang berarti rumah dan dibedakan atas [4] :

- Laika Mbuu, artinya rumah pokok. Disebut demikian karena bentuknya lebih besar dari pada rumah biasa, rumah semacam ini didirikan dipinggir kebun/ladang, menjelang akan 
dimulainya panen dan biasanya ditempati oleh beberap keluarga

- Laika landa, rumah sementara yang dihuni satu keluarga, didirikan di tepi kebun untuk persiapan panen

- Patande, adalah jenis rumah yang didirikan ditengah-tengah kebun sebagai tempat istirahat

- Laika Mborasaa, rumah jaga

- Laikandoiaha, rumah besar khusus tempat tinggal raja.

- Laika wuta, jenis rumah tempat tinggal yang lebih kecil dari laikalanda

- Laikawalanda, Jenis rumah yang panjang

- Kataba, yaitu rumah papan yang menggunakan sandi

\section{METODE PENELITIAN}

Penelitian ini akan mengeksplorasi nilai ruang dan bentuk rumah adat Tolaki dalam kaitannya dengan Kalo Sara sebagai unsur tertinggi dalam Tatanan Budaya Tolaki. Subyek yang akan diteliti adalah penafsiran Kalo Sara sebagai unsur budaya tertinggi dalam esensi budaya terhadap komposisi ruang, bentuk dan makna dalam rumah tradisional Tolaki.

Metode penelitian yang digunakan adalah metode Rasionalistik dengan pendekatan kualitatif. Teori-teori yang ada pada pendekatan rasionalistik, tidak mengikat hanya dipakai untuk langkah awal melihat obyek penelitian. Bentuk dari landasan teori ini adalah kualitatif yang digunakan sebagai alat untuk melihat kalosara dan menginterpretasikannya.

Pengambilan data dilakukan dengan observasi dan wawancara kepada para sesepuh dan tokoh masyarakat. Langkah penelitian adalah pengambilan data, dilanjutkan dengan pemilahan data baik berupa data gambar, foto, wawancara. Langkah berikutnya adalah menganalisis dengan bantuan teori dan dilanjutkan dengan interpretasi sebagai langkah akhir dari analisis.

\section{Landasan Teori}

Landasan teori yang akan digunakan sebagai kajian untuk membahas dan menganalisis tema ini sebagai berikut :

1. Teori Lokal Berupa,

a. masyarakat tolaki mempunyai Tujuh unsur kebudayaan yang menjadi tonggak dalam berkehidupan. Hakekat dari ketujuh unsur kebudayaan tersebut sangat terkait dengan simbol Budaya yang bernama "Kalo Sara" b. Kalo adalah ekspresi alam semesta dengan isinya, yaitu Hanu mendoda (alam nyata), Hanu Metoku ( alam bayangan), Hanu Tehi (alam gaib)

c. Alam nyata menurut orang Tolaki terdiri atas tiga bagian yaitu : Lahuena (langit). Wawowuta (permukaan bumi), Puriwuta (dasar bumi)

d. Hunian tradisional tolaki terkandung nilai mikrokosmis yang diatur dengan cara yang sama seperti alam.

2. Teori Nilai berupa teori tentang alasan manusia percaya terhadap sesuatu kekuatan yang dianggap lebih tinggi dan teori tentang alasan manusia melakukan beberapa hal dengan cara yang beraneka warna untuk mencari hubungan dengan kekuatan-kekuatan tadi.

3. Teori Hunian bahwa Rumah tradisional adalah gambaran duniawi citra sorgawi, yang mencakup poros bumi, pusar dunia, arah-arah pokok, sifat bulat, sifat segi empat panjang, semua merupakan upaya untuk membedakan daerah yang suci dan tidak suci.

\section{INTERPRETASI KALO SARA DALAM RUMAH TRADISIONAL TOLAKI}

Tatanan Rumah Tradisional Tolaki.

Rumah Tradisionil berbentuk rumah panggung yang menggunakan tiang-tiang bundar (tusa). Tidak menggunakan pondasi seperti halnya rumah-rumah tradisionnil yang lain. Tiang ditanam sedalam satu hasta. Tinggi tiang dari permukaan tanah hingga ke permukaan lantai diperkirakan kerbau bisa masuk di bawahnya; kurang lebih $2 \mathrm{~m}$. Jumlah tiang dalam rumah tradisional Tolaki minimal 9 tiang. Kesembilan tiang inilah yang menjadi core elemen dalam rumah tradisionil Tolaki.

Kesembilan tiang-tiang tersebut diperkuat oleh balok melintang (powuatako) dan memanjang (nambea). Dalam jajaran ke- 9 tiang ini terdapat satu tiang utama yang disebut dengan tiang petumbu yang terletak di tengah baris dan lajur kesembilan tiang ini. Tiang petumbu adalah tiang yang pertama kali ditanam dan pemasangannya dilakukan pada subuh hari (sebelum matahari terbit). Setelah petumbu didirikan, 4 hari atau lebih baru didirikan tiang-tiang lainnya dengan maksud untuk melihat dalam jangka waktu tersebut apakah akan terjadi sesuatu terhadap tiang petumbu. Jika tidak terjadi sesuatu maka dilakukan pemasangan kedelapan tiang yang lainnya. 
Setelah kesembilan tiang berdiri yang pertama dipasang adalah balok powuatako (A) pada sisi dalam tiang arah bagian belakang rumah, selanjutnya balok B dan C. Setelah balok powuatako dipasang selanjutnya pemasangan balok nambea (1) dimulai dari arah kanan rumah, kemudian menyusul nambea 2 dan nambea 3. Semua Powuatako dan nambea, baik yang melintang maupun yang memanjang yang menempel pada tiang dipinggir luar badan bangunan, harus ditempatkan di belakang tiang agar setelah dinding dipasang tiang tak akan kelihatan dari luar, karena terhalang oleh dinding.
Kesembilan tiang ini dalam bahasa Tolaki disebut siwolembatohu merupakan simbol dari delapan penjuru mata angin. Tiang petumbu merupakan pusat dari siwolembatohu. Oleh karena itu, inilah yang menjadi dasar pemikiran mengapa tiang petumbulah yang pertama kali dibangun bahkan dalam pemasangannya diikuti oleh upacara ritual dan pada bagian puncaknya selalu ada sesaji guna memohon kepada Tuhan agar seisi rumah yang menempati rumah ini dapat terhindar dari berbagai bahaya yang datang dari delapan penjuru mata angin.

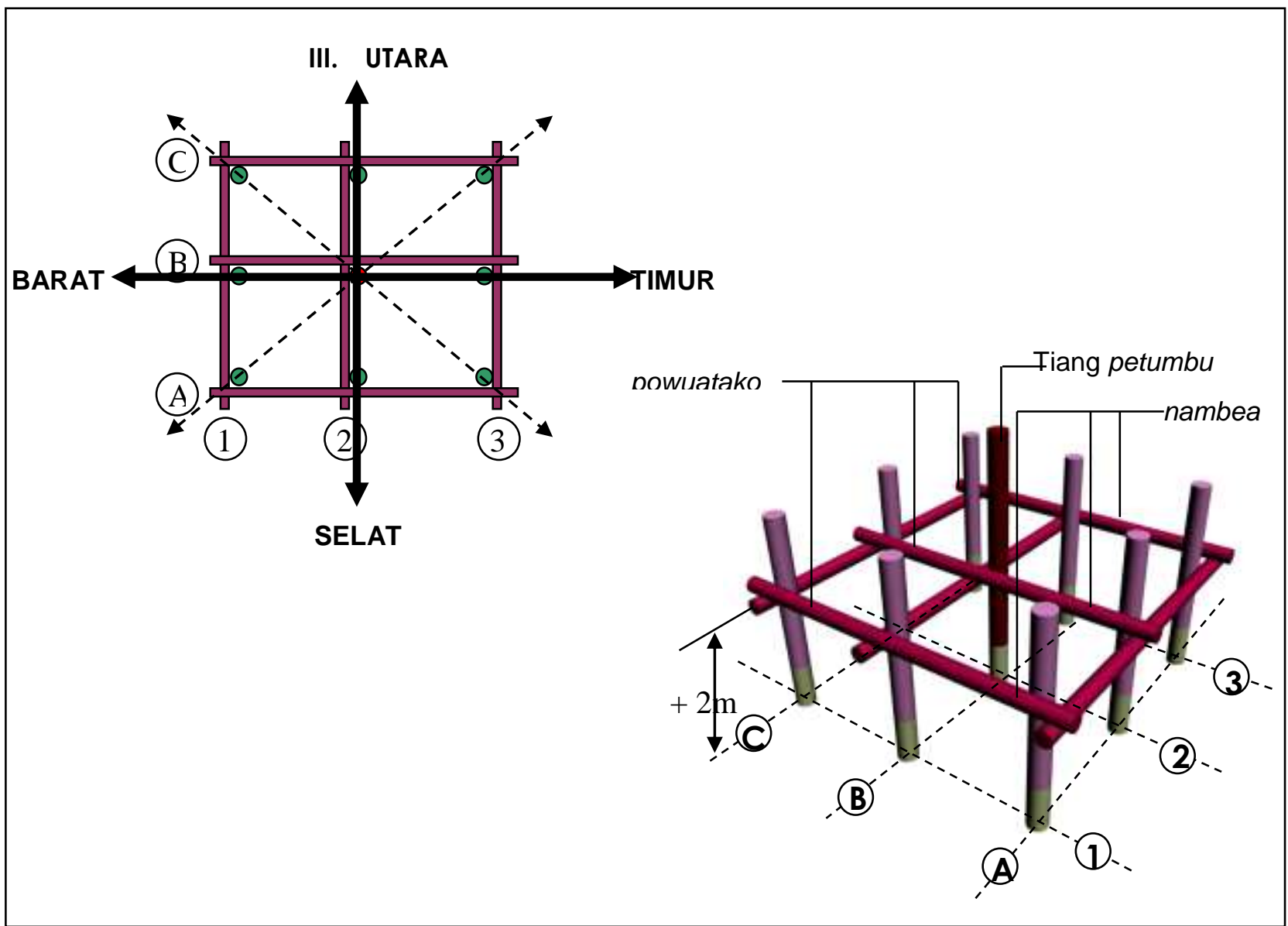

Gambar. 3.. Konfigurasi Sembilan Tiang Utama Sebagai Komponen Dasar Pembentuk Rumah Tolaki (Sumber : Hasil Penelitian, 2004)

\section{Tatanan Rumah Adat Tolaki}

Rumah adat Tolaki disebut dengan Nama Komali, yaitu rumah besar khusus raja Tolaki yang disebut Mokole. Jumlah tiang rumah adat Komali adalah 40 tiang di luar tiang dapur dan tiang teras. Makna dari jumlah 40 tiang ini terkait dengan suatu jumlah yang disyaratkan dalam peminangan yaitu 40 pinang dan 40 lembar daun sirih. Jadi perwujudan ini manifestasikan dalam tiang-tiang penopang rumah. Rumah Komali adalah induk dari rumah tradisional Tolaki Oleh karena itu proses pendirian rumah sebagaimana lazimnya rumah Tradisional dimulai dari pendirian sembilan tiang yang telah disebutkan diatas yaitu Siwolembatohu.

Tiang-tiang lainnya didirikan setelah ke-9 tiang ini jadi, barulah diikuti dengan pemasangan tiang yang lain. Arah pengembangan rumah mengarah pada ke-4 sisinya dalam hal ini 
pengembangan pada sisi depan lebih diutamakan karena bagian depan senantiasa digunakan sebagai ruang aktivitas adat. Balok yang mengikat kolom dan memikul lantai diikat di bawah balok-balok siwolembatohu, sehingga permukaan lantai pengembangan lebih rendah dari lantai siwolembatohu.

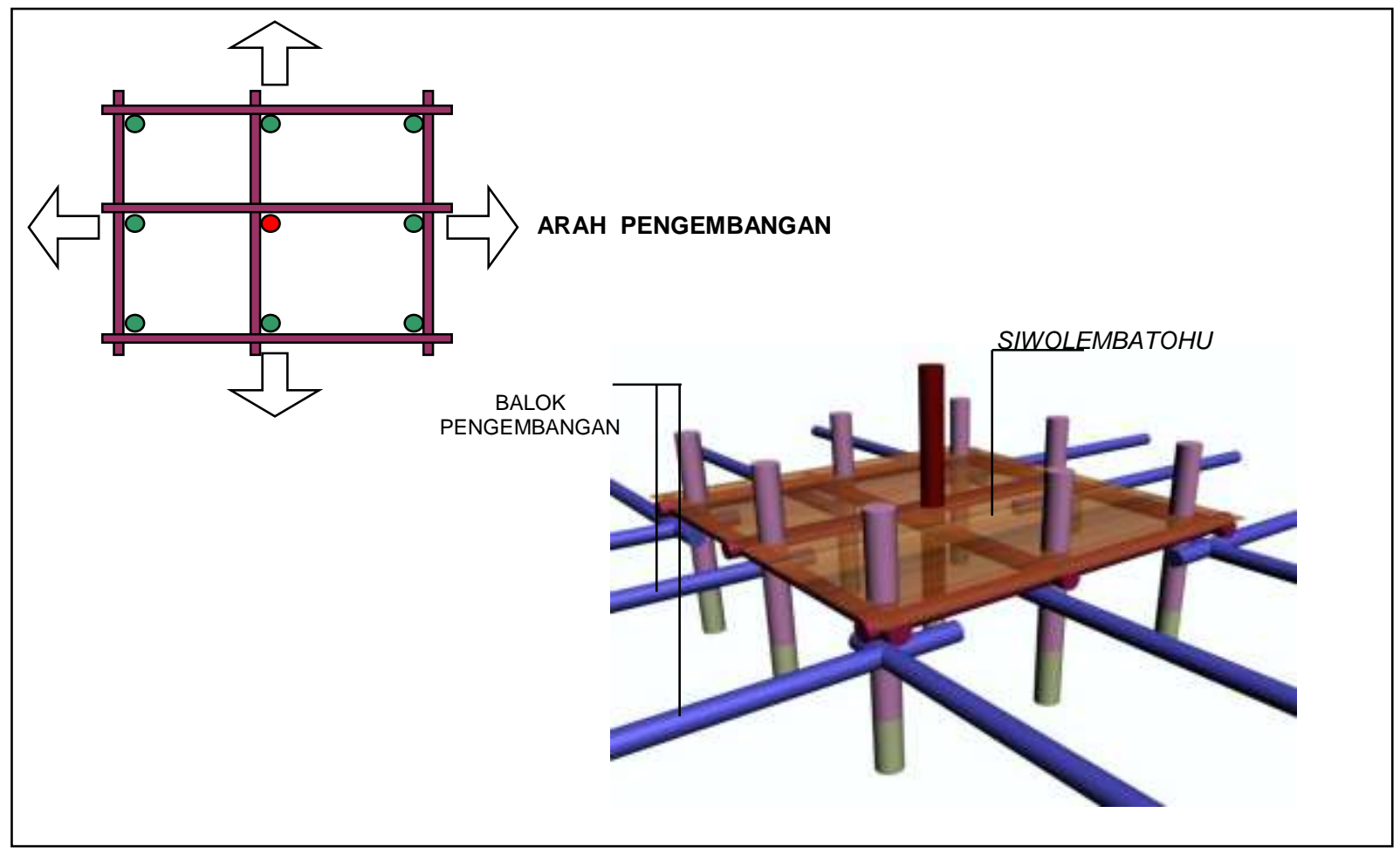

Gambar. 4. Arah pengembangan rumah dan kedudukan balok pengembangan terhadap posisi tiang-balok siwolembatohu

(Sumber : Rekonstruksi Peneliti, 2008)

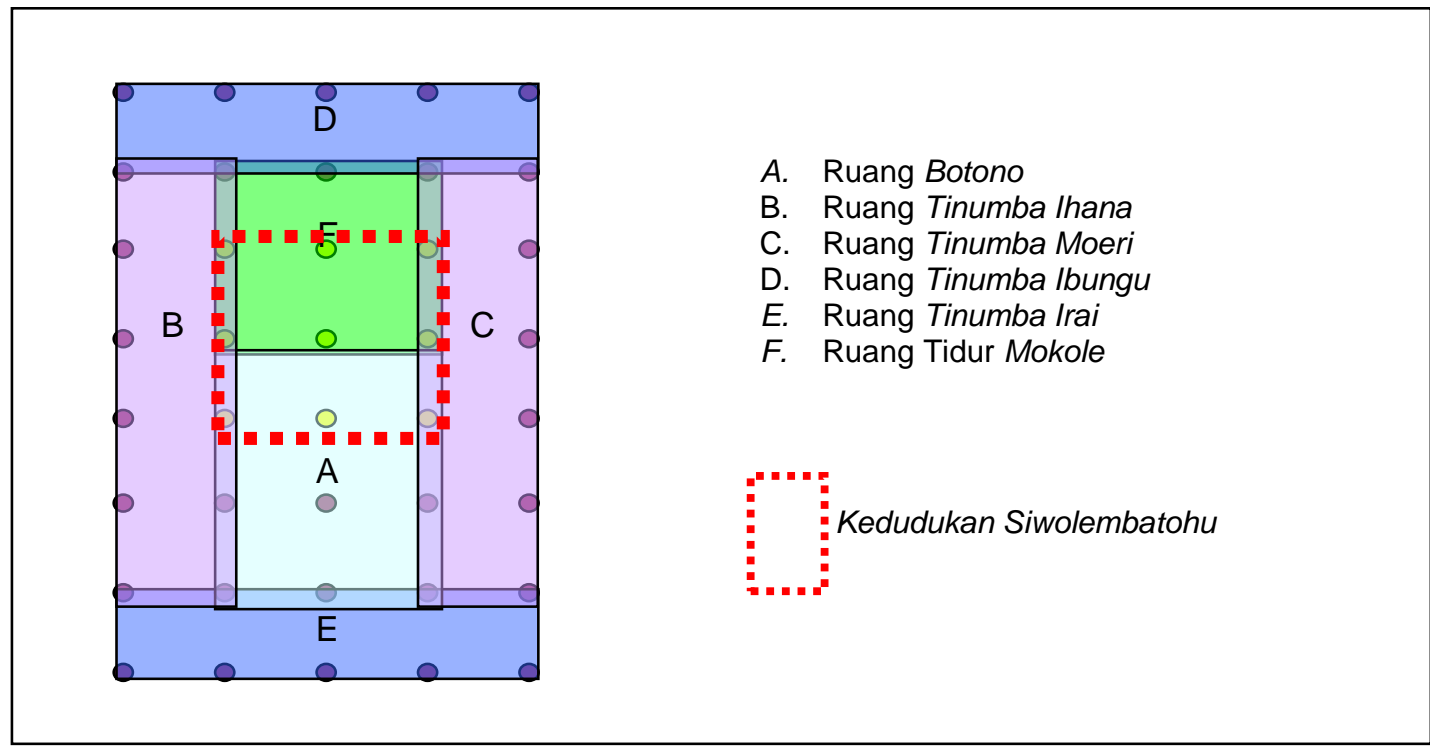

Gambar. 5.. Konfigurasi susunan lantai rumah Adat (Sumber : Rekonstruksi Penelitian Sachrul. 2008)

Konfigurasi ruang rumah adat Tolaki setelah dikembangkan, selalu terdiri atas empat bagian yaitu ; (1) tinumba ibungu, (2) tinumba irai, (3) tinumba moeri, (4) tinumba ihana dan (5) botono. Bagian belakang disebut tinumba ibungu mempunyai tinggi permukaan lantai sama dengan tinumba irai (depan), sedangkan tinumba moeri (kiri), tinumba ihana dan botono mempunyai permukaan lantai sama tinggi. Botono merupakan ruang tengah pada bagian 
siwolembatohu yang difungsikan sebagai ruang tidur mokole. Tinumba moeri biasa digunakan sebagai ruang tidur wanita dan tinumba ihana (kanan) biasa difungsikan sebagai ruang tidur pria. Tinumba ibungu biasa difungsikan sebagai ruang makan dan tinumba irai biasa berfungsi sebagai teras.

Teritori masing-masing lantai hanya dipisahkan oleh perbedaan ketinggian lantai dan jajaran tiang-tiang. Sekat nyata sebagai dinding pembatas ruang hanya terdapat pada ruang tidur mokole selebihnya hanya menggunakan tirai. Hal ini disebabkan agar daya tampung keluarga ketika diadakan aktivitas adat bisa lebih banyak, sehingga selalu membutuhkan ruang yang besar. Tirai digunakan sebagai pemisah ruang agar efisien untuk membenahi jika rumah tersebut akan dilangsungkan suatu aktivitas adat. Ruang tidur mokole terletak di bagian belakang ruang botono. Ruang tidur ini adalah satu-satunya ruang yang menggunakan dinding nyata sebagai pemisah.

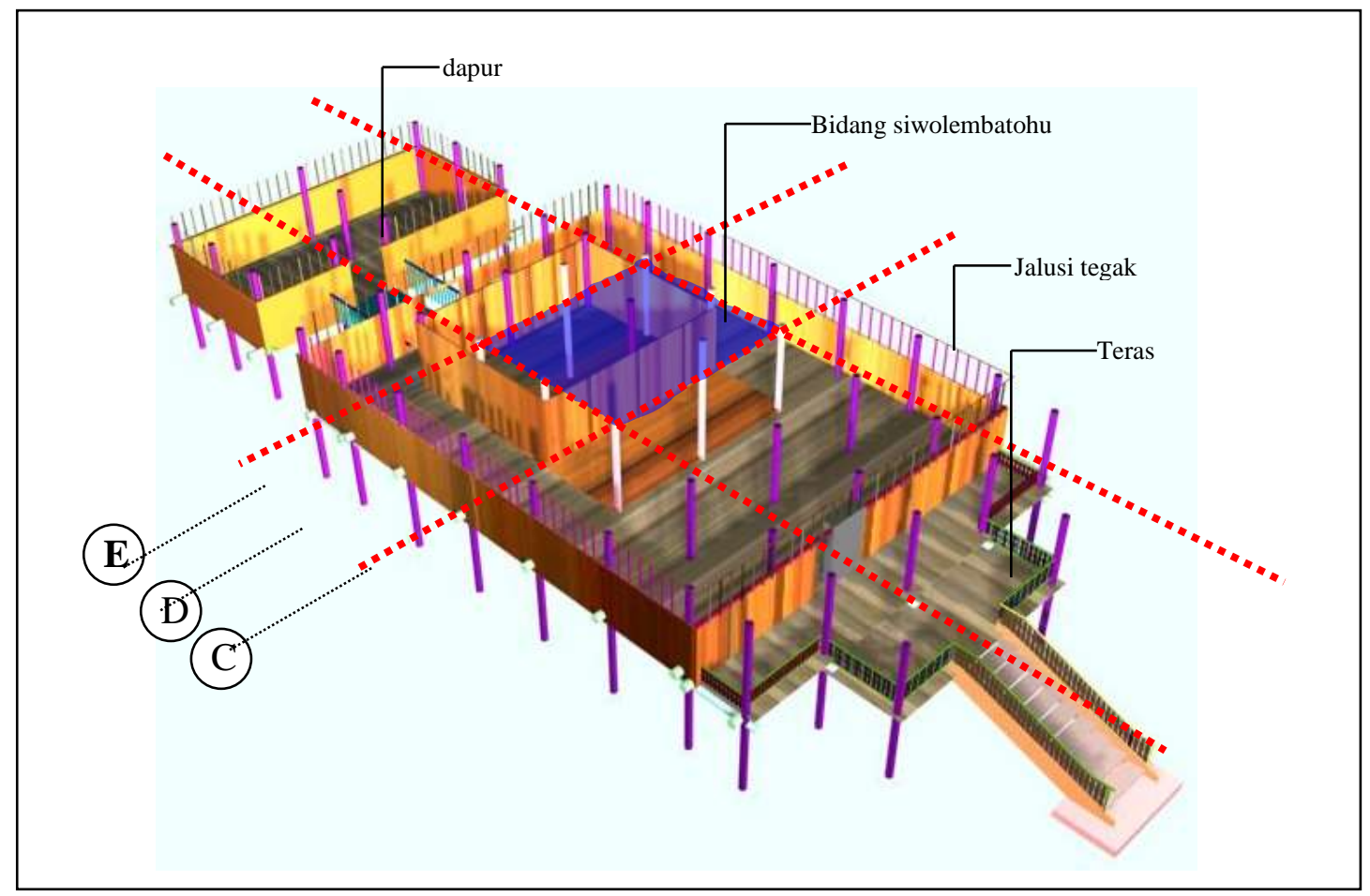

Gambar 6. Konfigurasi Lengkap susunan lantai rumah Adat komali

(Sumber : Rekonstruksi Peneliti, 2008)

Dapur dan ruang makan terletak di bagian belakang terpisah dengan badan rumah, dihubungkan dengan selasar. Dapur dibuat terpisah karena menghindari bahaya kebakaran dan menghindari asap masuk ke dalam rumah induk. Tempat tungku api berada pada posisi kiri rumah. Untuk patokan arah kanan dan kiri ketika kita berada dalam rumah dan menghadap ke arah depan. Bukaan berupa ventilasi mengelilingi dinding dapur. Pada bagian penghubung dapur terdapat sarika yaitu tempat duduk sepanjang penghubung yang biasa difungsikan sebagai tempat santai mokole. Atap dapur berbentuk perisai dengan bubungan tidak melengkung seperti pada bubungan rumah induk. Ketinggian lantai dapur serupa dengan ketinggian tinumba irai. Tangga terdapat pada bagian depan menempel pada tinumba irai dan bagian dapur melekat pada penghubung,
Anak tangga selalu berjumlah ganjil terbuat dari kayu bulat.

Loteng difungsikan sebagai ruang tidur wanita dan tempat menyimpan barang-barang berharga atau pusaka. Loteng tidak sepenuhnya menutupi permukaan lantai satu, tetapi membujur dari tiang $B$ hingga tiang ke tiang D (lihat Gambar 6). Akses ke loteng dihubungkan oleh anak tangga yang terdapat pada bagian belakang ruang tidur Mokole. Konon loteng sengaja ditempatkan tepat di atas ruang tidur mokole agar kemudahan kontrol terhadap anak gadis dan benda-benda berharga bisa maksimal dilakukan.

Secara keseluruhan atap berbentuk perisai dengan bagian bubungan melengkung. Batas lengkungan bubungan atap pada tiang $\mathrm{F}$ dan D (gambar 7 ) merupakan tiang penopang 
utama yang berjumlam 9 jajar tiang. Ragam hias yang terdapat di rumah komali adalah tanduk kerbau (tanu ngginiku) yang diletakkan di puncak atap bagian depan dan belakang serta ukiran model kepala pakis terdapat pada ujung lisplank.

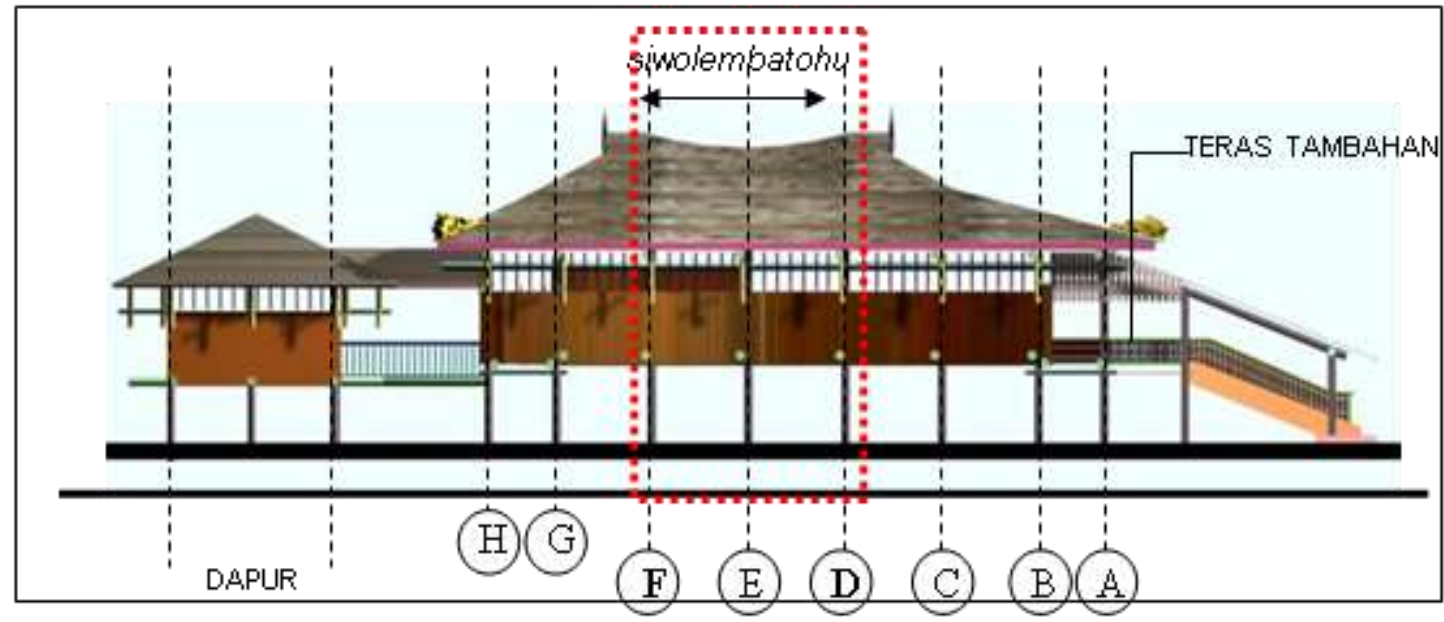

Gambar 7. Gambar Fasad Samping Memperlihatkan Bentuk Atap Melengkung (Sumber : Hasil Rekonstruksi Peneliti, 2008)

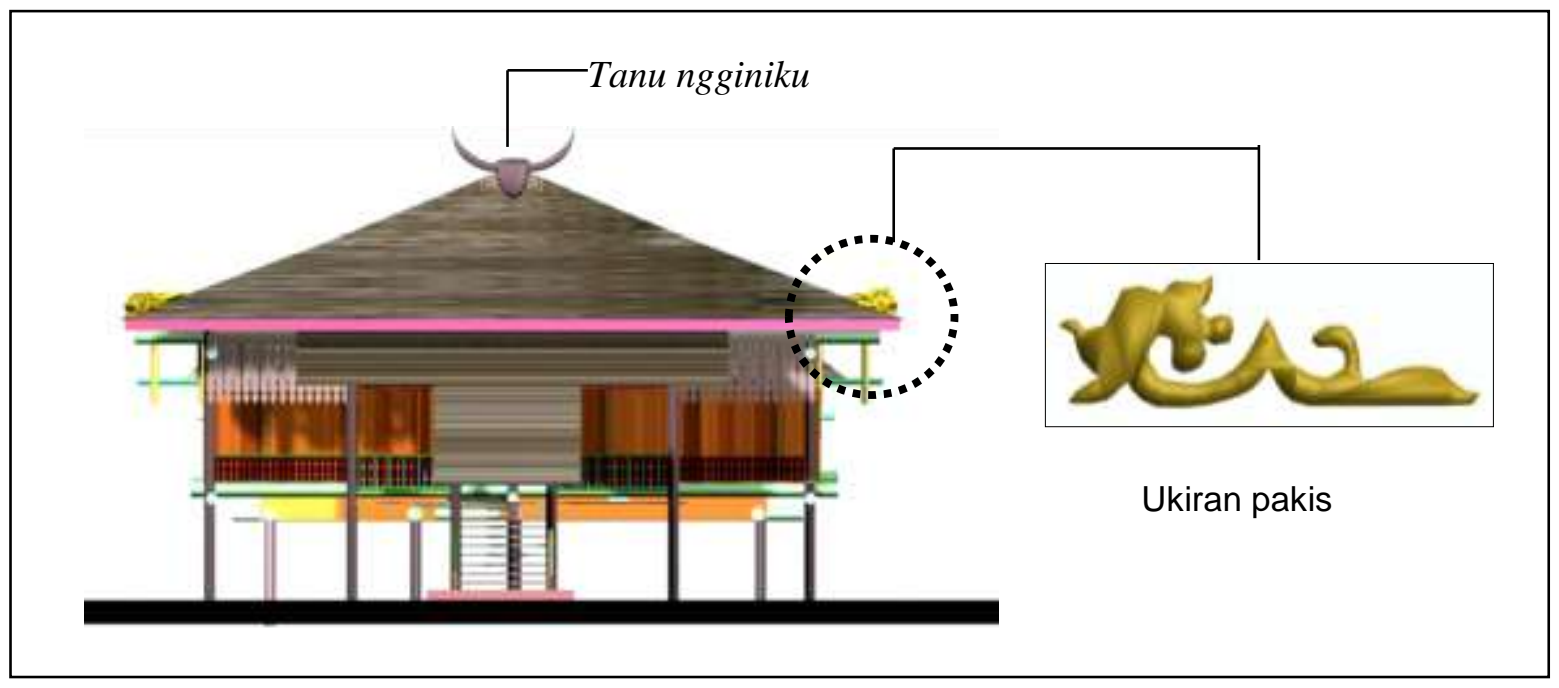

Gambar 8. Fasade Depan dan Jenis Ragam Hias di Rumah Komali (Sumber : Hasil Rekonstruksi Peneliti, 2008)

Makna tanduk kerbau adalah simbol kemakmuran masyarakat Tolaki. Kerbau merupakan hewan yang disakralkan karena pada setiap acara adat selalu menyembelih kerbau. Makin banyak kerbau yang disembelih makin menunjukkan tingginya status sosial mereka mengingat dahulu kerbau hanya dimiliki oleh para bangsawan. Berkaitan dengan makna ini maka tanduk kerbau merupakan simbol dari rumah para bangsawan.

\section{INTERPRETASI KALO SARA DALAM TATANA RUMAH TRADISIONIL}

Kalo terdiri atas 3 unsur yaitu : (1) unsur lingkaran yang terbuat dari bahan rotan yang dililit dan dipertemukan pada kedua ujungnya, (2) kain putih berbentuk segi empat, dan (3) anyaman motif pakis yang berbentuk segi empat. Dijelaskan dalam Tarimana Rauf bahwa di antara beberapa maknanya, kalo juga merupakan manifestasi dari hirarki cosmis. [1]. Hirarki tertinggi adalah lingkaran yang memanifestasikan dunia atas atau dunia suci (lahu ene). Hirarki kedua adalah kain putih yang memanifestasikan dunia tengah (wuta'aha) yaitu dunia tempat manusia bersosialisasi dan hirarki ke tiga adalah segi empat anyaman yang merupakan manifestasi dari dunia bawah atau nista (puri wuta). 


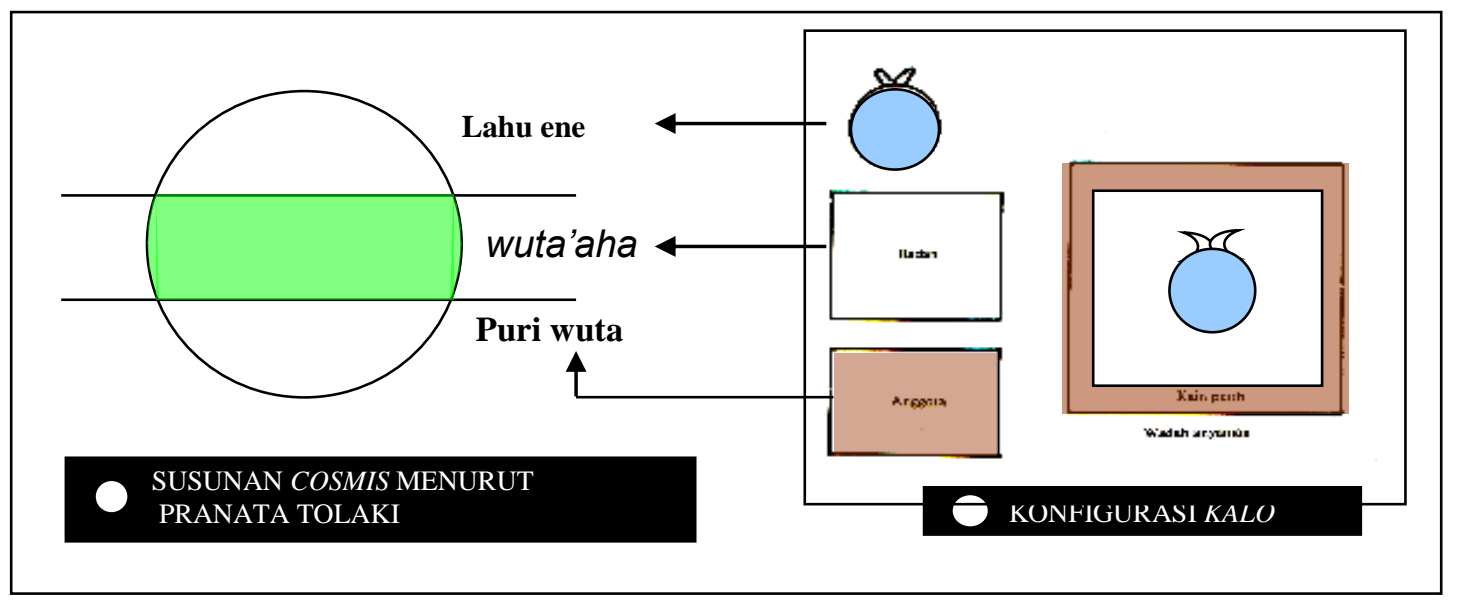

Gambar. 9. Susunan Kosmis dalam Paranata Budaya Tolaki kaitannya dengan Kalo (Sumber : Rekonstruksi Peneliti, 2008)

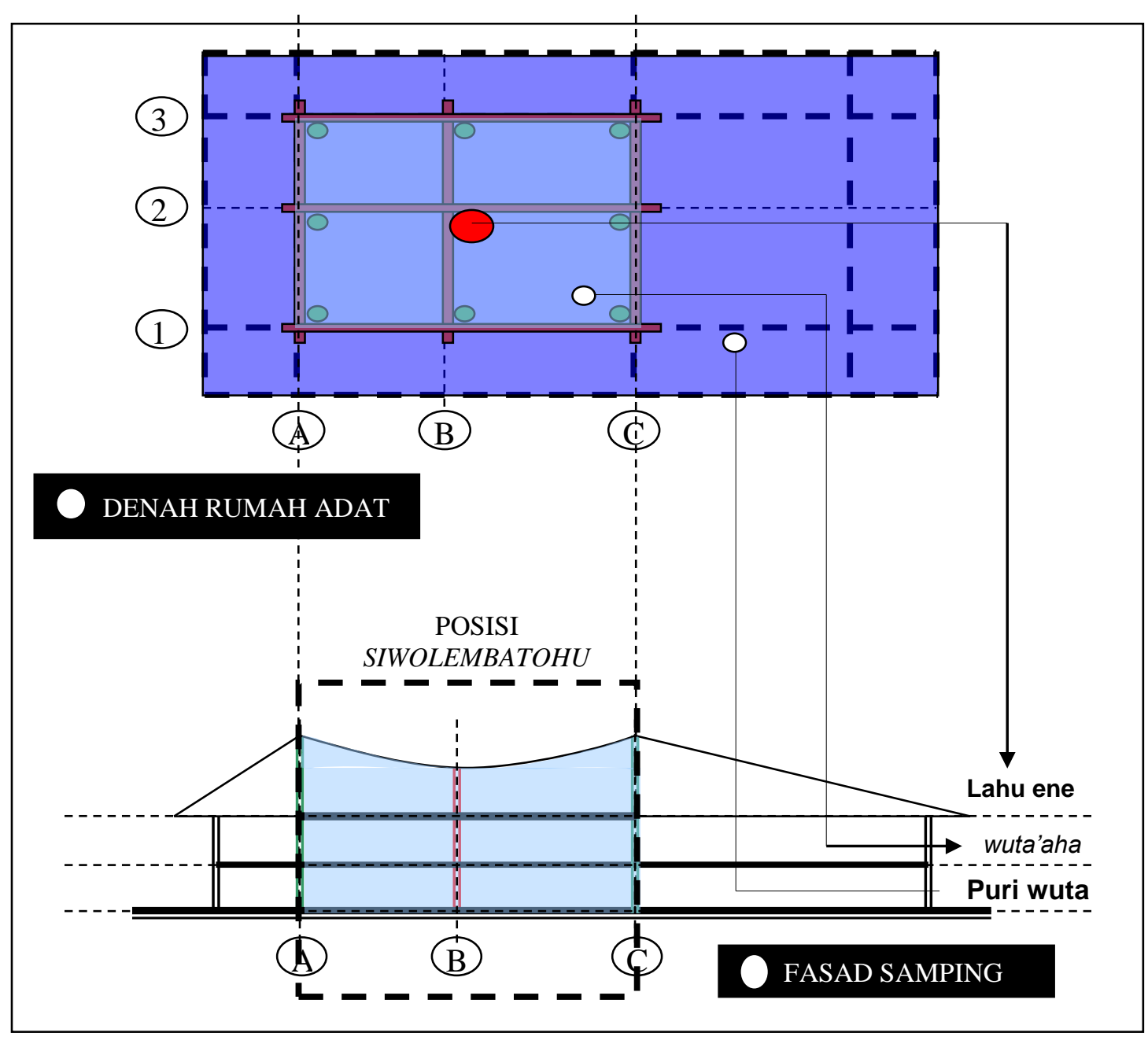

Gambar. 10. Manifestasi Kalo Sara Dalam Bentuk Rumah Tradisionil (Sumber : Hasil Rekonstruksi Peneliti, 2008) 


\section{KESIMPULAN}

Bagian inti yang disebut Siwolembatohu pada rumah adat Tolaki dirancang berdasarkan kaidah-kaidah kalo. Hal argumentatif yang berkaitan dengan makna ini terjelaskan berdasarkan fungsi-fungsi ruang. Pada bagian loteng, fungsi ruang adalah tempat memingit gadis remaja dan menyimpan barang-barang berharga. Jadi kenyataan ini berkaitan dengan makna benda yang disimpan yang identik dengan sesuatu yang suci dan sakral (gadis=suci, benda berharga=sakral). Jadi ruang loteng mengandung nilai-nilai kesakralan. Dalam susunan kalo bagian teratas adalah lingkaran rotan yang mempunyai hirarki tertinggi di antara ketiga susunannya, manifestasi untuk mengungkapkan bahwa loteng merupakan bagian dari susunan ruang rumah yang paling sakral dan dibahasakan dalam bentuk bubungan yang melengkung yang merupakan manifestasi dari lingkaran kalo.

Fungsi rumah pada bagian badan adalah tempat berlangsungnya kehidupan dan peri kehidupan. Di badan rumah inilah tempat keluarga bersosialisasi dan menjalankan aktivitas budaya antara sesama manusia.
Ungkapan ini juga sama dengan makna susunan kalo yang terbuat dari kain putih berbentuk segi empat yaitu hubungan antara sesama manusia. Sementara pada bagian kolong rumah hanya difungsikan sebagai ruang ternak (ikat kerbau) dan tidak digunakan sebagai ruang aktivitas manusia. kerena sesuai dengan pranata budaya Tolaki bahwa kolong adalah dunia bawah, dunia kotor dan dunia nista. Jadi simbol ini telah berakar dalam kognitif map mereka sehingga pantang (pomali) untuk melakukan aktivitas di kolong.

\section{DAFTAR PUSTAKA}

[1] Rauf, Tarimana. (1993). Kebudayaan Tolaki. Balai Pustaka. Jakarta.

[2] Rapoport, A. (1969). House Form and Culture. Prentice-Hall. Inc. Ngelwood Cliffs. N.J.

[3] Triyanto. (2001). Rumah Kudus. Kelompok Studi Mekar, Semarang

[4] Lakebo. (1986). Arsitektur Tradisional Sulawesi Tenggara. Proyek Inventarisasi Kebudayaan Daerah. Depdikbud. Jakarta. 